\title{
High-Rate and Efficient Ethylene Electrosynthesis Using a Catalyst/Promoter/ Transport Layer
}

Adnan Ozden, ${ }^{\perp}$ Fengwang Li, ${ }^{\perp}$ F. Pelayo García de Arquer, Alonso Rosas-Hernández, Arnaud Thevenon, Yuhang Wang, Sung-Fu Hung, Xue Wang, Bin Chen, Jun Li, Joshua Wicks, Mingchuan Luo, Ziyun Wang, Theodor Agapie,* Jonas C. Peters,* Edward H. Sargent,* and David Sinton*

Cite This: ACS Energy Lett. 2020, 5, 2811-2818

Read Online

ABSTRACT: Carbon dioxide $\left(\mathrm{CO}_{2}\right)$ electroreduction to valuable chemicals such as ethylene is an avenue to store renewable electricity and close the carbon cycle. Membrane electrode assembly (MEA) electrolyzers have attracted recent interest in light of their high stability and despite low productivity (a modest partial current density in $\mathrm{CO}_{2}$-toethylene conversion of approximately $100 \mathrm{~mA} \mathrm{~cm}^{-2}$ ). Here we present an adlayer functionalization catalyst design: a catalyst/tetrahydro-phenanthrolinium/ionomer (CTPI) interface in which the catalytically active copper is functionalized using a phenanthrolinium-derived film and a perfluorocarbon-based polymeric ionomer. We find, using electroanalytical tools and operando spectroscopies, that this hierarchical adlayer augments both the local $\mathrm{CO}_{2}$ availability and the adsorption of the key reaction intermediate $\mathrm{CO}$ on the catalyst surface. Using this

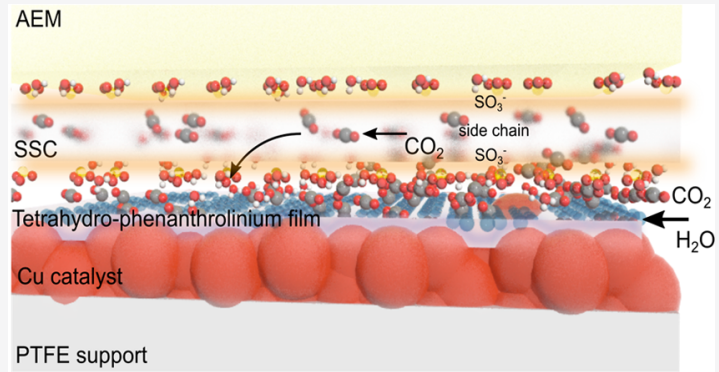

Enrichment of $\mathrm{CO}_{2}$ and ${ }^{*} \mathrm{CO}$ at catalyst surfaces favors $\mathrm{CO}_{2}$-to-ethylene conversion CTPI catalyst, we achieve an ethylene Faradaic efficiency of $66 \%$ at a partial current density of $208 \mathrm{~mA} \mathrm{~cm}^{-2}-\mathrm{a} 2$-fold increase over the best prior MEA electrolyzer report-and an improved full-cell energy efficiency of $21 \%$.

$\mathrm{T}$ he electrochemical $\mathrm{CO}_{2}$ reduction reaction $\left(\mathrm{CO}_{2} \mathrm{RR}\right)$ offers storage of intermittent electricity from solar and wind in the form of fuels and value-added chemicals, ${ }^{1-3}$ enabling further penetration of renewables in the transportation and chemical industries. ${ }^{4-8}$

Implementation of $\mathrm{CO}_{2} \mathrm{RR}$ will require high productivity to reduce capital cost and high energy efficiency (EE) to reduce operating cost. Techno-economic assessments further emphasize the need for high activity in generating high-value $\mathrm{CO}_{2} \mathrm{RR}$ products, such as ethylene, well beyond the $100 \mathrm{~mA} \mathrm{~cm}{ }^{-2}$ threshold. ${ }^{9,10}$ Conventional $\mathrm{H}$-cells deliver current densities of only tens of $\mathrm{mA} \mathrm{cm} \mathrm{cm}^{-2}$ because of $\mathrm{CO}_{2}$ mass transport limitations in aqueous solutions. ${ }^{11,12}$

Introducing $\mathrm{CO}_{2}$ in the gas phase enables facile $\mathrm{CO}_{2}$ mass transport from the bulk to the local electrode by decreasing the thickness of the diffusion layer from tens of micrometers to tens of nanometers, permitting $\mathrm{CO}_{2} \mathrm{RR}$ current densities above $100 \mathrm{~mA} \mathrm{~cm}{ }^{-2} \cdot{ }^{13-15}$ In such a flow-cell configuration, a gas diffusion electrode (GDE) separates gas-phase $\mathrm{CO}_{2}$ from either alkaline or neutral electrolyte. ${ }^{16,17}$ However, ohmic loss across the neutral electrolyte that extends between cathode and anode leads to a high overpotential when the current density is high, limiting EE. ${ }^{18}$ Though the use of alkaline electrolyte increases ionic conductivity and enables higher current densities and EEs, ${ }^{17}$ the formation of carbonate salt from the reaction of $\mathrm{CO}_{2}$ with alkali electrolyte wastes reactant $\mathrm{CO}_{2}$, reduces system stability, and increases cost. ${ }^{8}$

Membrane electrode assembly (MEA) electrolyzers form an integrated layered stack by removing the catholyte and merging the cathode/ion-exchange membrane/anode (Figure 1a). ${ }^{16-20}$ MEAs developed for fuel cells and water electrolyzers achieved current densities $>1 \mathrm{~A} \mathrm{~cm}^{-2} \cdot{ }^{21-23}$ However, with present day MEAs, $\mathrm{CO}_{2} \mathrm{RR}$ activities toward ethylene are still limited to approximately $100 \mathrm{~mA} \mathrm{~cm}{ }^{-2} \cdot 18,24,25$

Received: June 10, 2020

Accepted: August 6, 2020 

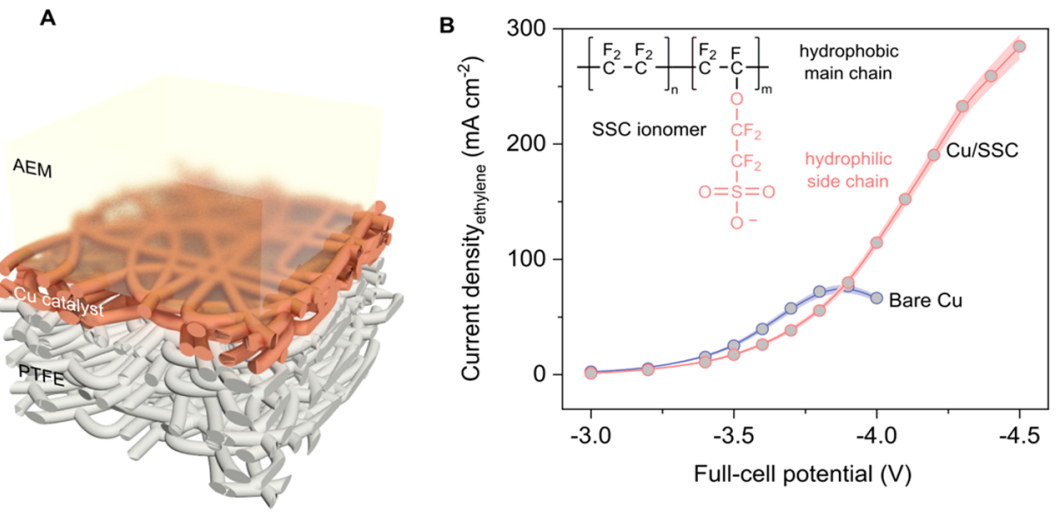

C
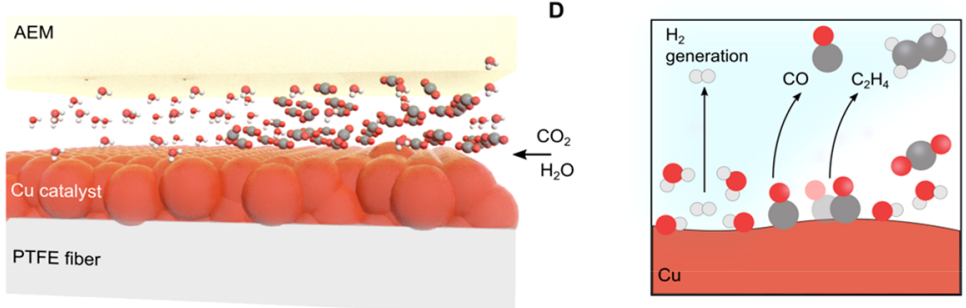

E
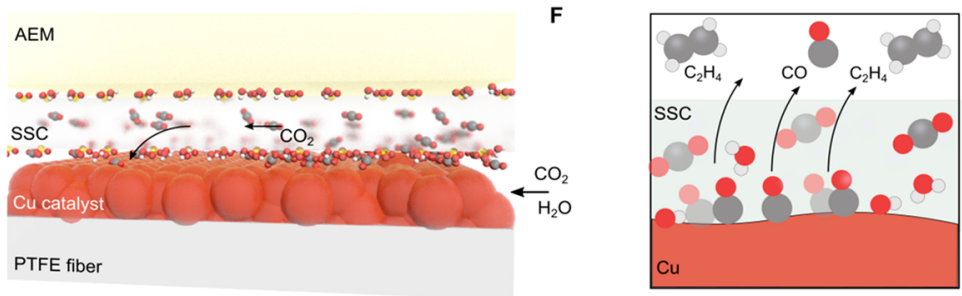

Figure 1. Ionomer-augmented $\mathrm{CO}_{2}$ availability in an MEA electrolyzer. (A) $\mathrm{Cu}$ /PTFE electrode and its interface with the AEM. (B) Ethylene partial current densities under a range of applied voltage for bare Cu/PTFE and SSC-modified Cu/PTFE electrodes. Inset $B$ describes the chemical structure of the SSC ionomer. The SSC is composed of a hydrophobic PTFE backbone and a hydrophilic side chain terminated by sulfonic acid. Full-cell potentials are presented without $i R$ compensation. The $\mathrm{CO}_{2} \mathrm{RR}$ electrolysis was operated using $\mathrm{CO}_{2}$ with a flow rate of $80 \mathrm{sccm}, 0.1 \mathrm{M} \mathrm{KHCO}_{3}$ anolyte with a flow rate of $20 \mathrm{~mL} \mathrm{~min}{ }^{-1}$. (C) Limited $\mathrm{CO}_{2}$ availability on unmodified Cu surface. The schematic illustrates the local $\mathrm{CO}_{2}$ and $\mathrm{H}_{2} \mathrm{O}$ transport for a single $\mathrm{Cu} / \mathrm{PTFE}$ fiber in the cross-sectional direction. (D) Competition between the $\mathrm{CO}_{2} \mathrm{RR}$ and HER on unmodified $\mathrm{Cu}$ surface. The limited $\mathrm{CO}_{2}$ availability surface dominates the competing HER over $\mathrm{CO}_{2} \mathrm{RR}$ at elevated current densities. (E) Enrichment of $\mathrm{CO}_{2}$ species in the local reaction environment enabled by SSC ionomer conformably surrounding Cu surface. The schematic illustrates the local $\mathrm{CO}_{2}$ and $\mathrm{H}_{2} \mathrm{O}$ transport for a single Cu/PTFE fiber coated with the SSC ionomer in the crosssectional direction. (F) Dominancy of the $\mathrm{CO}_{2} \mathrm{RR}$ over the HER upon SSC ionomer modification. Note: SSC stands for SSC ionomer.

Here we present a hierarchical adlayer-a catalyst/tetrahydro-phenanthrolinium/ionomer (CTPI) structure-that enables high-rate and efficient electrosynthesis of ethylene in an MEA electrolyzer. In this design, the catalytically active copper is modified by a phenanthrolinium-derived molecular film and a perfluorocarbon-based polymeric ionomer. This hierarchical adlayer augments simultaneously the availability of reactant $\mathrm{CO}_{2}$ and the binding strength of $* \mathrm{CO}$, a key intermediate along the pathway to ethylene. ${ }^{26,27}$ These two factors contribute to current densities and EEs in $\mathrm{CO}_{2} \mathrm{RR}$.

We achieve as a result ethylene partial current densities greater than $200 \mathrm{~mA} \mathrm{~cm}{ }^{-2}$ - a 2-fold enhancement in rate compared to the best prior reports in MEA electrolyzers. ${ }^{18,24}$ We do this with an ethylene Faradaic efficiency (FE) of $66 \%$ and a full-cell EE of $21 \%$, the highest selectivity and the highest efficiency reported for MEA-based $\mathrm{CO}_{2} \mathrm{RR}$ electrolyzers.

We sought to diagnose the origins of low current densities in MEA electrolyzers. Using polycrystalline $\mathrm{Cu}$ (150 nm thick) sputtered on a porous polytetrafluoroethylene (PTFE, average pore size of $450 \mathrm{~nm}$ ) gas diffusion layer (Figure S1) as the cathode $(\mathrm{Cu} / \mathrm{PTFE})$, iridium oxide supported on a titanium mesh as the anode, and an anion exchange membrane (AEM) as the solid-state electrolyte, we assembled the MEA (Figure S2) and explored the $\mathrm{CO}_{2} \mathrm{RR}$ performance at the voltage range of -3 to $-4.5 \mathrm{~V}$. Both total current density and ethylene FE increase with increasing voltage, and the peak ethylene $\mathrm{FE}$ reaches $45 \%$ at $-3.8 \mathrm{~V}$. This trend results in a peak ethylene partial current density of $\sim 75 \mathrm{~mA} \mathrm{~cm}$ c $^{-2}$ (Figure 1b). The limiting current density was positively correlated with the partial pressure of $\mathrm{CO}_{2}$ supplied (Figure S3), suggesting that local $\mathrm{CO}_{2}$ concentration is one factor that could limit the reaction rate. The full-cell EE was $14 \%$ based on eq 1 :

$$
\mathrm{EE}=\frac{E^{\circ}}{E_{\text {applied }}} \times \mathrm{FE}_{\text {ethylene }}
$$

where $E^{\circ}$ is $1.15 \mathrm{~V}$, the thermodynamic potential for the overall reaction $2 \mathrm{CO}_{2}+2 \mathrm{H}_{2} \mathrm{O} \rightarrow \mathrm{C}_{2} \mathrm{H}_{4}+3 \mathrm{O}_{2}$.

It is suggested that the $\mathrm{CO}_{2}$ concentration decreases rapidly at the gas/liquid/solid three-phase interface (Figure 1c): 
A

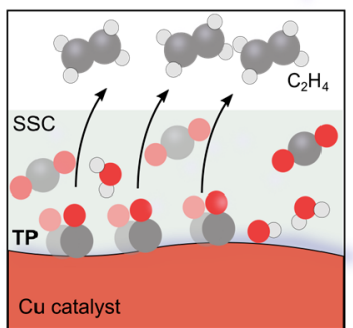

B

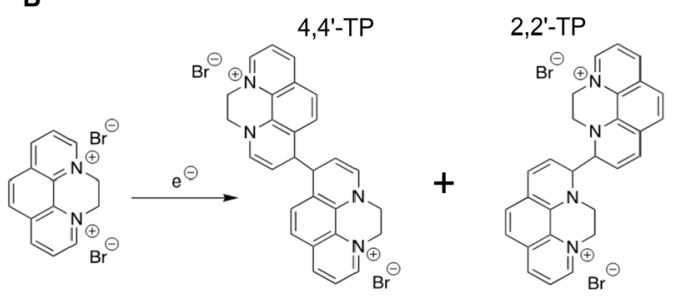

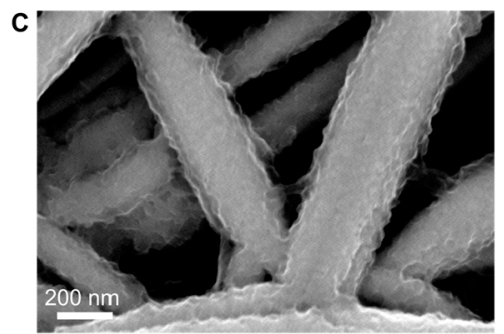
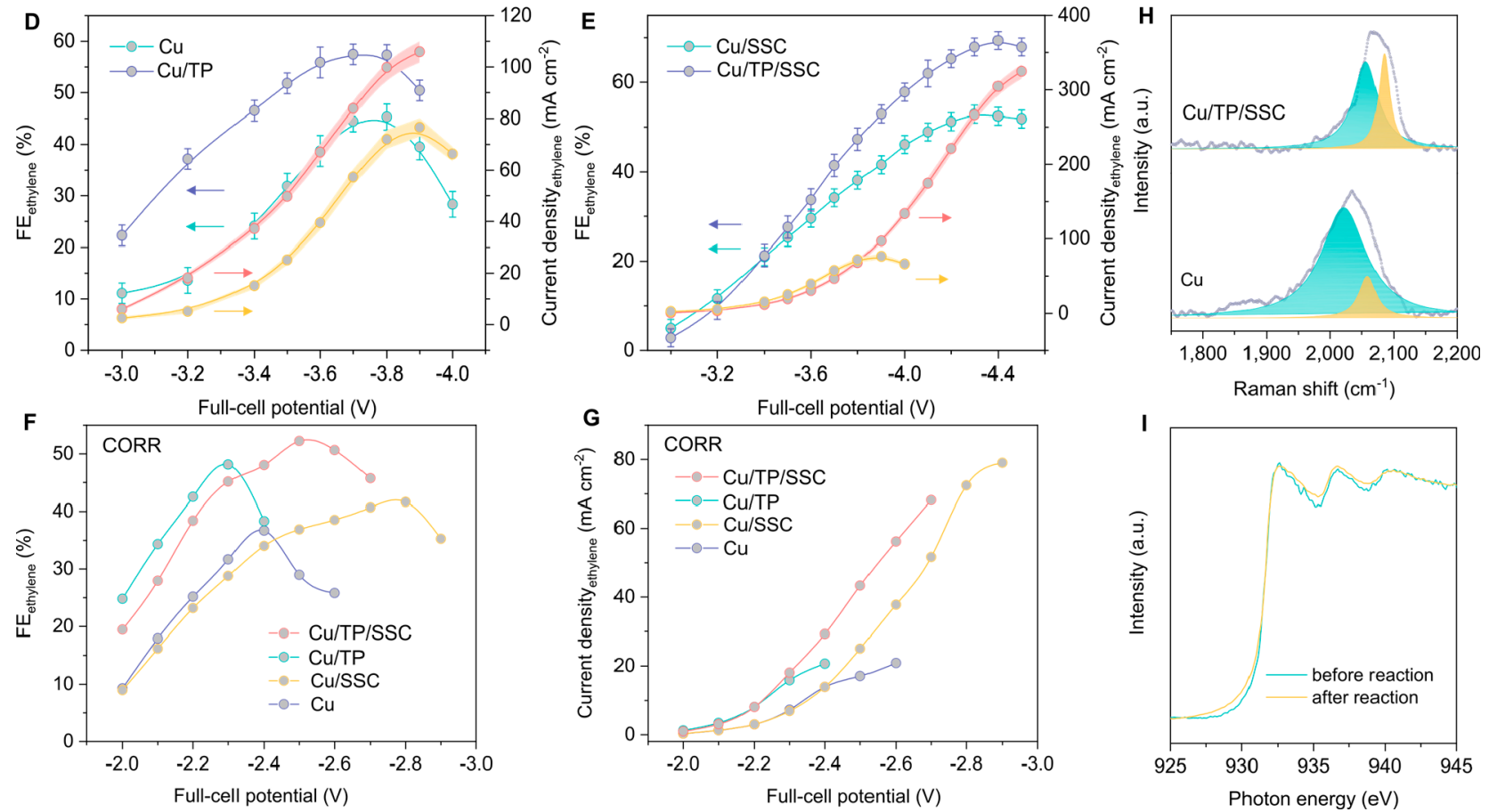

Figure 2. $\mathrm{CO}_{2}$-to-ethylene conversion in an MEA electrolyzer. (A) Hierarchical tetrahydro-phenanthrolinium/ionomer modified Cu/PTFE surface allows more $\mathrm{CO}_{2}$ and ${ }^{*} \mathrm{CO}$. (B) Electrodimerization of the phenanthrolinium into the 4,4' and 2,2'-tetrahydro-phenanthrolinium dimeric structures. (C) SEM images of tetrahydro-phenanthrolinium/ionomer on Cu/PTFE. (D) Ethylene FE and partial current density for unmodified Cu/PTFE (yellow line) and tetrahydro-phenanthrolinium-modified Cu/PTFE (red line). (E) Ethylene FE for SSC-modified Cu/ PTFE, and ethylene FE and partial current density for tetrahydro-phenanthrolinium/SSC-modified Cu/PTFE (red line), and ethylene partial current density for unmodified $\mathrm{Cu} / \mathrm{PTFE}$ (yellow line). Full-cell potentials of the $\mathrm{CO}_{2} \mathrm{RR}$ electrolysis are presented without $i R$ compensation. The $\mathrm{CO}_{2} \mathrm{RR}$ electrolysis was operated using $\mathrm{CO}_{2}$ with a flow rate of $80 \mathrm{sccm}, 0.1 \mathrm{M} \mathrm{KHCO}$ anolyte with a flow rate of $20 \mathrm{~mL}$ $\min ^{-1}$. (F) Ethylene FE for unmodified Cu/PTFE, SSC-modified Cu/PTFE, tetrahydro-phenanthrolinium-modified Cu/PTFE, and tetrahydro-phenanthrolinium/SSC-modified Cu/PTFE for CO-to-ethylene conversion. (G) Ethylene partial current density for unmodified $\mathrm{Cu}$ /PTFE, SSC-modified Cu/PTFE, tetrahydro-phenanthrolinium-modified Cu/PTFE, and tetrahydro-phenanthrolinium/SSC-modified $\mathrm{Cu} /$ PTFE for CO-to-ethylene conversion. Full-cell potentials of the CORR electrolysis are presented without $i R$ compensation. The CORR electrolysis was operated using $\mathrm{CO}$ with a flow rate of $80 \mathrm{sccm}, 3 \mathrm{M} \mathrm{KOH}$ anolyte with a flow rate of $20 \mathrm{~mL} \mathrm{~min}^{-1}$. (H) Raman spectra of tetrahydro-phenanthrolinium/SSC ionomer modified Cu/PTFE and unmodified Cu/PTFE (the areas highlighted in blue and yellow indicate the bridge and atop adsorptions of $\mathrm{CO}$ on the $\mathrm{Cu}$ surface, respectively). (I) XAS spectra of the tetrahydro-phenanthrolinium/SSCmodified Cu/PTFE. Note: TP and SSC stand for tetrahydro-phenanthrolinium and SSC ionomer, respectively.

because $\mathrm{CO}_{2} \mathrm{RR}$ uses water as the proton source ${ }^{26}$ and generates local hydrated $\mathrm{OH}^{-}$, a significant portion of the catalyst surface is likely inaccessible to $\mathrm{CO}_{2},{ }^{28,29}$ and the competing HER dominates in these areas (Figure 1d).

We took the view that $\mathrm{CO}_{2} \mathrm{RR}$ kinetics would increase if the transport of $\mathrm{CO}_{2}$ to catalyst surfaces was unimpeded by $\mathrm{OH}^{-} /$ $\mathrm{H}_{2} \mathrm{O}$, i.e. with separate gas and ion/liquid transport channels that improve $\mathrm{CO}_{2}$ transport and avoid consumption of $\mathrm{CO}_{2}$ by $\mathrm{OH}^{-}$. We took inspiration from the role of ionomers in the enhancement of oxygen reduction reaction (ORR) kinetics in fuel cells through concurrent transport of reactants, byproducts, and charged species ${ }^{30,31}$ and explored the viability of ionomers on $\mathrm{CO}_{2} \mathrm{RR}$ performance of $\mathrm{Cu}$ catalysts. We reasoned that the hydrophobic and hydrophilic segments of the ionomer would allow the transport of gas and hydrated ions, respectively. ${ }^{32}$

We formed nanometer-thick polymeric films via the spraycoating of an ionomer solution onto the $\mathrm{Cu} / \mathrm{PTFE}$ substrate and tested $\mathrm{CO}_{2} \mathrm{RR}$ performance (Figure $\mathrm{S} 4$ for the morphology). A short-side-chain (SSC) perfluorocarbon polymer $^{32,33}$ (Figure 1b) was used as the ionomer. It is composed of a hydrophobic PTFE backbone and a hydrophilic side chain terminated by sulfonic acid. We found that the SSC extends the ethylene partial current density to $280 \mathrm{~mA} \mathrm{~cm}-2$ (Figures $1 \mathrm{~b}$ and $\mathrm{S} 5$ ). The increased current density is attributed to increased $\mathrm{CO}_{2}$ transport achieved by the separation of $\mathrm{CO}_{2}$ and ion $/ \mathrm{H}_{2} \mathrm{O}$ pathways. As in prior reports, $^{32,34}$ a much larger portion of the catalyst becomes 

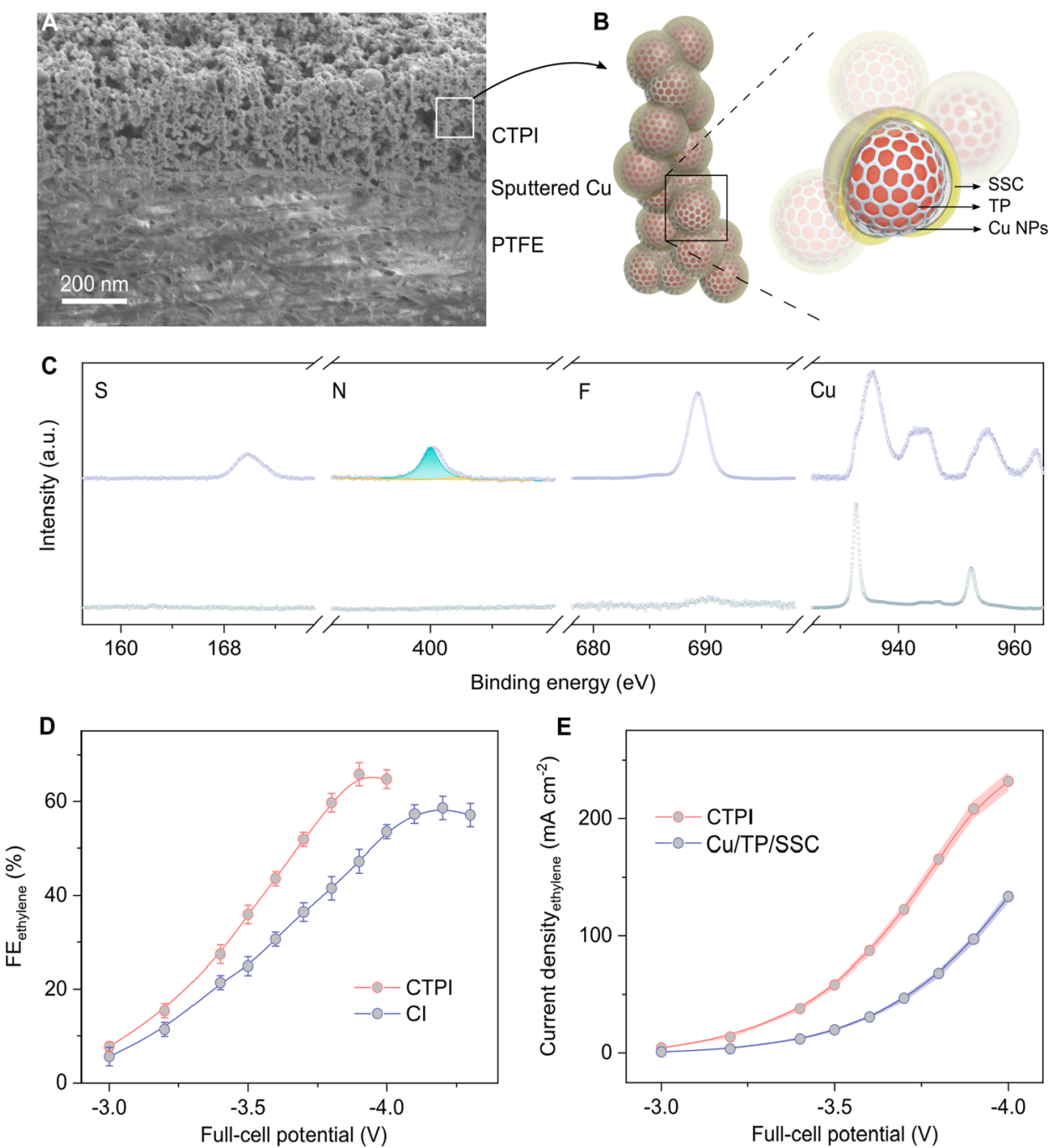

Figure 3. 3D CTPI catalyst enables selective and efficient $\mathrm{CO}_{2}$-to-ethylene conversion in an MEA electrolyzer. (A) Cross-sectional SEM image of the tetrahydro-phenanthrolinium/SSC ionomer hierarchy established together with $\mathrm{Cu}$ NPs on a Cu/PTFE substrate. (B) Schematic illustration of the tetrahydro-phenanthrolinium/SSC ionomer hierarchy on Cu NPs. (C) XPS spectra of the 3D CTPI catalyst. (D) Ethylene FE for 3D CTPI (tetrahydro-phenanthrolinium/SSC-modified Cu NPs on Cu/PTFE) and 3D CI (SSC modified-Cu NPs on $\mathrm{Cu}$ /PTFE) for $\mathrm{CO}_{2}$-to-ethylene conversion. (E) Ethylene partial current density for 3D CTPI (tetrahydro-phenanthrolinium/SSC-modified $\mathrm{Cu}$ NPs on Cu/PTFE) and 2D CTPI (tetrahydro-phenanthrolinium/SSC-modified Cu/PTFE (Cu/TP/SSC)). Full-cell potentials are presented without $i R$ compensation. The $\mathrm{CO}_{2} \mathrm{RR}$ electrolysis was operated using $\mathrm{CO}_{2}$ with a flow rate of $80 \mathrm{sccm}, 0.1 \mathrm{M} \mathrm{KHCO}$ anolyte

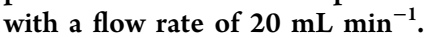

accessible to gas $\left(\mathrm{CO}_{2}\right)$ via a hydrophobic backbone while the transport of ions $/ \mathrm{H}_{2} \mathrm{O}$ is retained within hydrophilic side chains (Figure 1e,f). This effect is akin to the well-coordinated, simultaneous transport of $\mathrm{O}_{2}$ and proton $/ \mathrm{H}_{2} \mathrm{O}$ transports in fuel cells. ${ }^{30,31}$ The length of the side chain in the ionomer does not markedly affect the productivity of ethylene from $\mathrm{CO}_{2} \mathrm{RR}$ (Figure S6). Although the partial current density for ethylene is increased to $>200 \mathrm{~mA} \mathrm{~cm}{ }^{-2}$, the ethylene $\mathrm{FE}$ around $52 \%$ is only slightly higher than that of the reference $\mathrm{Cu} / \mathrm{PTFE}$ case, and the high $(-4.5 \mathrm{~V})$ potential required (Figures $1 \mathrm{~b}$ and $\mathrm{S} 5$ ) renders a low full-cell $\mathrm{EE}<15 \%$. We realized that, at the optimum voltage for the reference $\mathrm{Cu} / \mathrm{PTFE},-3.8 \mathrm{~V}$, the $\mathrm{FE}$ toward $\mathrm{CO}$ for the SSC-modified $\mathrm{Cu}$ is $25 \%$ while that for the $\mathrm{Cu} / \mathrm{PTFE}$ is $13 \%$. Converting the excess CO to ethylene while maintaining a similar applied voltage would improve EE.

We sought to introduce a further adlayer on catalyst surfaces with an organic film functioning similar to pyridinium-derived films. ${ }^{24,35}$ We postulated that conformal hierarchical deposition of such a layer together with SSC ionomer on the $\mathrm{Cu}$ surfacewithout disrupting SSC benefits and blocking the catalytically active sites (Figure S7) - may optimize the binding of $* \mathrm{CO}$ and therefore promote CO-to-ethylene conversion (Figure 2a).

We electro-reduced $\mathrm{N}, \mathrm{N}^{\prime}$-ethylene-phenanthrolinium dibromide onto the $\mathrm{Cu} / \mathrm{PTFE}$ catalyst to form a $20 \pm 5 \mathrm{~nm}$ continuous and conformal film (Figure S8) comprising primarily the $4,4^{\prime}$ and $2,2^{\prime}$ dimeric structures (Figures $2 b$ and S9), in accordance with previous findings on polycrystalline copper. ${ }^{35}$ While it is possible that during extended storage the molecular film composition evolves (Figure S9), for example via partial oxidation, its $\mathrm{CO}_{2} \mathrm{RR}$ performance is high even after a period of weeks. We then spray-deposited the electrode with a $15 \pm 5 \mathrm{~nm}$ SSC ionomer layer, and the resulting electrode possessed a morphology similar to that of the unmodified $\mathrm{Cu} / \mathrm{PTFE}$ (Figures 2c, S1, and S10).

We found that the phenanthrolinium-derived molecular film enables an improved ethylene FE. Applying the optimal 

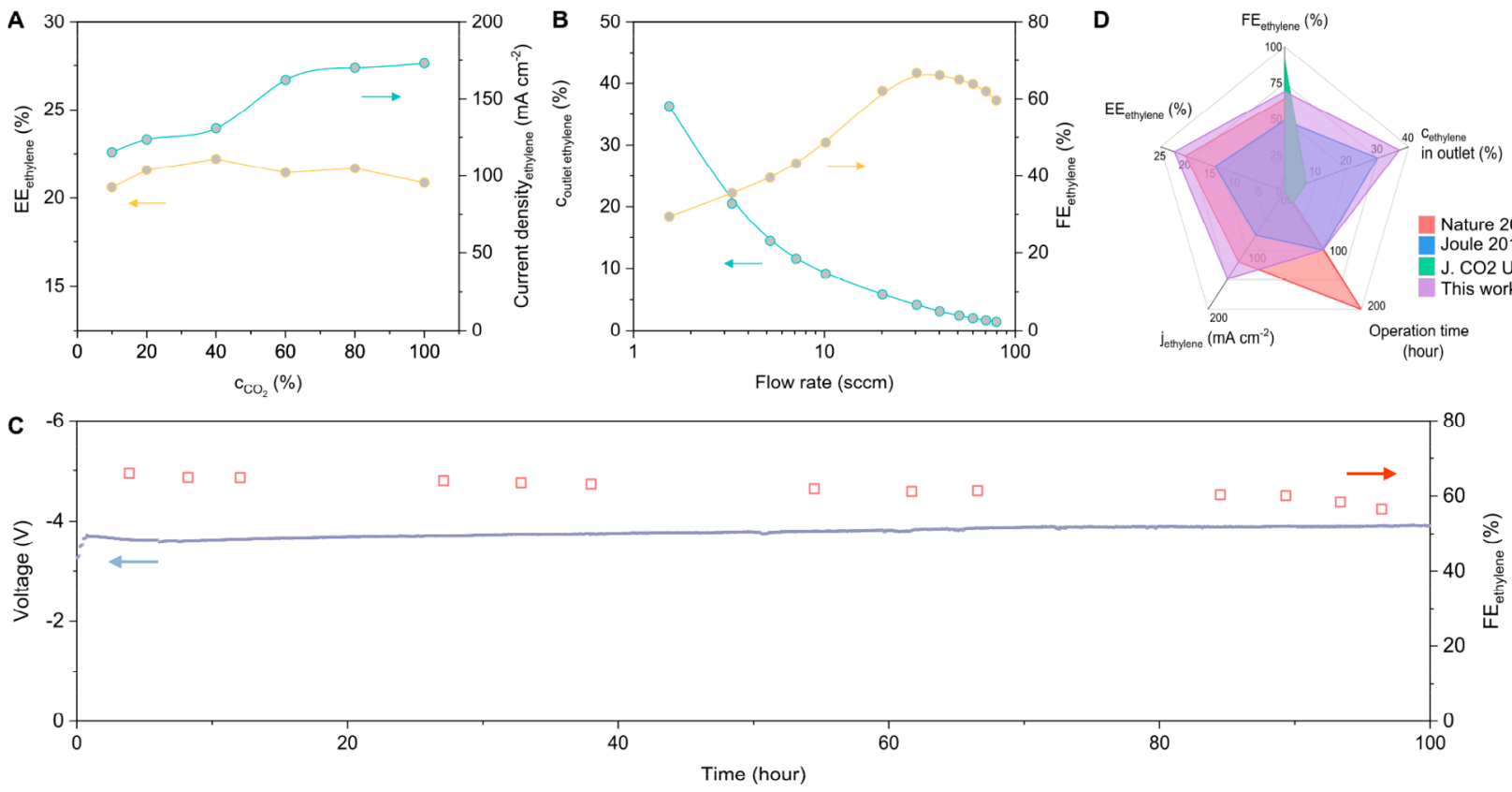

Figure 4. Applied $\mathrm{CO}_{2} \mathrm{RR}$ performance of the 3D CTPI catalyst in an MEA electrolyzer. (A) Full-cell EEs and ethylene partial current densities as a function of $\mathrm{CO}_{2}$ concentration in a diluted $\mathrm{CO}_{2}$ stream. (B) Ethylene concentrations in the cathode outlet and FEs as a function of $\mathrm{CO}_{2}$ flow rate. The $\mathrm{CO}_{2} \mathrm{RR}$ electrolysis was operated using $\mathrm{CO}_{2}$ with a flow rate of $80 \mathrm{sccm}, 0.1 \mathrm{M} \mathrm{KHCO}_{3}$ anolyte with a flow rate of $20 \mathrm{~mL} \mathrm{~min}^{-1}$. (C) Extended $\mathrm{CO}_{2} \mathrm{RR}$ performance of the 3D CTPI catalyst at a constant current density of $220 \mathrm{~mA} \mathrm{~cm}$ and with a feeding gas of $\mathrm{CO}_{2} / \mathrm{N}_{2}(40 \% / 60 \%)$ at a flow rate of $80 \mathrm{sccm}$. The anolyte was $0.1 \mathrm{M} \mathrm{KHCO}_{3}$ with a flow rate of $20 \mathrm{~mL} \mathrm{~min}^{-1}$. The blue line represents the voltage recorded during the extended $\mathrm{CO}_{2} \mathrm{RR}$ experiment (primary $y$-axis). Each red square represents the ethylene $\mathrm{FE}$ averaged from three independent measurements (secondary $y$-axis). (D) Comparison of the performance metrics of the MEA electrolyzer based on 3D CTPI catalyst with literature benchmarks (for each report, the plotted values are those from the longest duration test).

tetrahydro-phenanthrolinium loading to the $\mathrm{Cu} / \mathrm{PTFE}$ surface (Figure S11), we achieved an ethylene FE of $58 \%$ at an applied voltage of $-3.7 \mathrm{~V}$ (Figures $2 \mathrm{~d}$ and $\mathrm{S} 12$ ). The increased ethylene $\mathrm{FE}$ at the expense of $\mathrm{CO} \mathrm{FE}$ (Figure S12) is consistent with a prior report. ${ }^{24}$ Mainly because of the improved FE, the full-cell EE improved from $14 \%$ for the reference $\mathrm{Cu} / \mathrm{PTFE}$, to $18 \%$.

Although the ethylene $\mathrm{FE}$ is high for the tetrahydrophenanthrolinium-modified $\mathrm{Cu} / \mathrm{PTFE}$ catalyst, the partial current density was capped at around $110 \mathrm{~mA} \mathrm{~cm}{ }^{-2}$, in agreement with the picture of limited $\mathrm{CO}_{2}$ transport. To recover the already-achieved high current density observed in the SSC-modified $\mathrm{Cu} / \mathrm{PTFE}$ case, we reintroduced the outermost SSC layer to the tetrahydro-phenanthroliniummodified $\mathrm{Cu} / \mathrm{PTFE}$ catalyst (see Figures $2 \mathrm{c}$ and S13 for the SEM images). We found that the FE and partial current density toward ethylene are increased, especially at the applied voltage region where the $\mathrm{CO}_{2} \mathrm{RR}$ is otherwise limited by $\mathrm{CO}_{2}$ mass transport, as in the case of tetrahydro-phenanthroliniummodified $\mathrm{Cu} /$ PTFE electrode (Figure 2e). By optimizing the tetrahydro-phenanthrolinium loading and the hierarchical ordering in the tetrahydro-phenanthrolinium/SSC film (Figures $\mathrm{S} 14$ and S15), we achieved (at $-4.4 \mathrm{~V}$ ) a peak ethylene FE of $69 \%$ with a partial current density of $304 \mathrm{~mA} \mathrm{~cm}^{-2}$, both of which are the highest performance metrics for $\mathrm{CO}_{2} \mathrm{RR}$ MEA electrolyzers to date. The full-cell EE is $18 \%$, a value similar to that achieved by the tetrahydro-phenanthrolinium-modified $\mathrm{Cu}$, because of the compromise between increased ethylene FEs and simultaneously increased applied potentials.

By performing electrochemical impedance spectroscopy (EIS) measurements, we found that modification of the $\mathrm{Cu}$ / PTFE electrode with tetrahydro-phenanthrolinium or together with SSC ionomer does not substantially change the resistances at the interface (Table S1), thus yielding similar cell resistances overall (Figure S16).

This tetrahydro-phenanthrolinium molecule was reported in a recent flow cell electrolyzer study, with operating current densities lower than $10 \mathrm{~mA} \mathrm{~cm}{ }^{-2}, 35$ and has not been applied to GDE-based $\mathrm{CO}_{2} \mathrm{RR}$ MEA electrolyzers. To clarify the COadsorption enhancing role of the tetrahydro-phenanthrolinium in this new system, we used $\mathrm{CO}$ as a probe molecule and carried out the $\mathrm{CO}$ reduction reaction (CORR) using $3 \mathrm{M}$ $\mathrm{KOH}$ as the anolyte, a condition that has been proven to promote CORR. ${ }^{36,37} \mathrm{We}$ found that the tetrahydro-phenanthrolinium-modified $\mathrm{Cu} / \mathrm{PTFE}$ shows a higher ethylene $\mathrm{FE}$ (Figure 2f) and partial current density (Figure 2g) in both cases, with and without the SSC layer. We note also that the SSC ionomer layer promotes higher current densities, benefiting from the improved availability of $\mathrm{CO}$ near the active sites, akin to the case of $\mathrm{CO}_{2}$.

Using in situ Raman spectroscopy, we found that the tetrahydro-phenanthrolinium increases the ratio of atop- to bridge- bound $\mathrm{CO}$ from 0.14 on $\mathrm{Cu}$ to 0.51 (Figure $2 \mathrm{~h}$ ), an optimum value we found previously ${ }^{24}$ that resulted in a low activation barrier for $\mathrm{C}-\mathrm{C}$ coupling, the first step in CORR. ${ }^{26,27,38}$ We further confirmed that the modification of the tetrahydro-phenanthrolinium on $\mathrm{Cu}$ does not promote $\mathrm{CO}_{2} \mathrm{RR}$ through the tuning of Cu's electronic structure, a finding we concluded from the unaltered $\mathrm{Cu}$ L-edge soft X-ray adsorption spectroscopy (XAS) on the tetrahydro-phenanthrolinium deposited $\mathrm{Cu} / \mathrm{PTFE}$ upon $1 \mathrm{~h}$ electrolysis at an applied voltage of $-3.7 \mathrm{~V}$ (Figure $2 \mathrm{i}$ ).

We sought further to improve current densities at similar, if not increased, EEs. A prior report ${ }^{18}$ has shown that a lower 
$\mathrm{CO}_{2}$ partial pressure favors the ethylene selectivity, which the authors attributed to a high local $\mathrm{pH}$ by mitigating the reaction of $\mathrm{OH}^{-}$with excess $\mathrm{CO}_{2}$. However, at the relatively high current densities tested here, lowering $\mathrm{CO}_{2}$ partial pressure decreases current density because of less reactant $\mathrm{CO}_{2}$ availability. Instead, we extended the developed CTPI architecture into three dimensions by establishing a tetrahydro-phenanthrolinium/ionomer hierarchy together with $\mathrm{Cu}$ nanoparticles (NPs) on a Cu/PTFE substrate (Figure 3a,b): more active sites lead to higher current densities per geometric area and thus meanwhile consume more $\mathrm{CO}_{2}$ by $\mathrm{CO}_{2} \mathrm{RR}$, resulting in less $\mathrm{CO}_{2}$ "free" to react with $\mathrm{OH}^{-}$.

We spray-coated a homogeneous dispersion of $\mathrm{Cu}$ NPs, tetrahydro-phenanthrolinium, and SSC ionomer, onto the $\mathrm{Cu}$ / PTFE substrate (see Figure S17 for the morphology and microstructure of the mortem electrodes). The tetrahydrophenanthrolinium precursor was electro-dimerized in situ when $\mathrm{CO}_{2} \mathrm{RR}$ was initiated in the MEA (Figure S18), establishing a highly porous catalyst composed of $\mathrm{Cu}$ NPs/tetrahydrophenanthrolinium/SSC ionomer (Figure S19). The X-ray photoelectron spectroscopy (XPS) peaks corresponding to $S$ $2 \mathrm{p}, \mathrm{N} 1 \mathrm{~s}, \mathrm{~F} 1 \mathrm{~s}$, and $\mathrm{Cu} 2 \mathrm{p}$ confirm the presence of each component in the $\mathrm{Cu} \mathrm{NPs/tetrahydro-phenanthrolinium/SSC}$ catalyst upon completion of $\mathrm{CO}_{2} \mathrm{RR}$ (Figure 3c). The $\mathrm{N} 1 \mathrm{~s}$ spectrum consists of two peaks located at 400.2 and $402.5 \mathrm{eV}$, indicating that the tetrahydro-phenanthrolinium includes tertiary amine and quaternary ammonium, consistent with the prior report. ${ }^{35}$ The thickness of sputtered $\mathrm{Cu}$; loadings of $\mathrm{Cu}$ NPs; and the ratios among Cu NPs, SSC ionomer, and tetrahydro-phenanthrolinium were optimized (Figures S20S23). We observed the typical gas and liquid products for $\mathrm{CO}_{2} \mathrm{RR}$ with a total $\mathrm{FE}$ of $\sim 100 \%$ (Figure S24).

We investigated the electrochemical performance of the 3D CTPI catalyst in an MEA electrolyzer in neutral media. The electro-dimerized molecular film resulted in an increased ethylene FE compared to the control samples (Figure 3d). The working principle is similar to the planar CTPI catalyst: the tetrahydro-phenanthrolinium promotes ethylene selectivity via favorable conversion of CO (Figure S25), and the SSC ionomer enables higher reaction rates by enhanced $\mathrm{CO}_{2}$ transport.

The extended reaction interface provided by the $3 \mathrm{D}$ catalyst yielded improved reaction rates compared to its $2 \mathrm{D}$ counterpart at lower full-cell voltages (Figures $3 \mathrm{e}$ and S25), reaching an ethylene partial current density of $208 \mathrm{~mA} \mathrm{~cm}^{-2}$ at only $-3.9 \mathrm{~V}$. In contrast, the $2 \mathrm{D}$ catalyst provides $97 \mathrm{~mA} \mathrm{~cm}^{-2}$ at the same potential. The full-cell EE is $21 \%$ for the $3 \mathrm{D}$ CTPI catalyst, slightly higher than the best prior value in MEA electrolyzers, ${ }^{24}$ but along with a $2.8 \times$ larger current density.

We further assessed the performance of 3D CTPI catalyst under challenging conditions: a diluted $\mathrm{CO}_{2}$ stream, ${ }^{39}$ a direct intake of flue gas, ${ }^{10,40}$ and a variable $\mathrm{CO}_{2}$ feed rate. ${ }^{17} \mathrm{We}$ simulated the dilution of $\mathrm{CO}_{2}$ streams (down to $10 \%$ ) via cofeeding with $\mathrm{N}_{2}$. The $3 \mathrm{D}$ CTPI catalyst maintained ethylene partial current densities $>120 \mathrm{~mA} \mathrm{~cm}{ }^{-2}$, along with EEs over $20 \%$, at all concentrations including $10 \% \mathrm{CO}_{2}$ (Figures $4 \mathrm{a}$ and S26). Markedly, it yields an ethylene FE of $69 \%$ at $-3.7 \mathrm{~V}$ at a $40 \% \mathrm{CO}_{2}$ concentration, corresponding to a full-cell $\mathrm{EE}$ of $22 \%$. We further assessed the 3D CTPI catalyst using a simulated flue gas composed of $\mathrm{CO}_{2}$ (15.1\%), $\mathrm{O}_{2}$ (3.99\%), CO (190 ppm), $\mathrm{SO}_{2}$ (698 ppm), and $\mathrm{N}_{2}$ (balance). The 3D CTPI catalyst yields FEs toward ethylene of $22 \%$ at $-3.8 \mathrm{~V}$, whereas the reference $\mathrm{Cu} / \mathrm{PTFE}$ provides an ethylene $\mathrm{FE}$ below $5 \%$ across -3 to $-4.0 \mathrm{~V}$ (Figure S27). The direct intake of flue gas decreases selectivity toward $\mathrm{CO}_{2} \mathrm{RR}$ at the current densities investigated (Figure S28). This is ascribed to the parasitic ORR, ${ }^{4}$ which is thermodynamically more favorable than $\mathrm{CO}_{2} \mathrm{RR}$ by more than $1 \mathrm{~V}$, as well as the poisoning of catalysts by $\mathrm{SO}_{2}{ }^{42}$

We varied the $\mathrm{CO}_{2}$ flow rate 25 -fold ( 80 to $3 \mathrm{sccm}$ ) while performing $\mathrm{CO}_{2} \mathrm{RR}$ with the $3 \mathrm{D}$ CTPI catalyst at a constant current density of $300 \mathrm{~mA} \mathrm{~cm}{ }^{-2}$. The ethylene $\mathrm{FE}$ reached a peak of $67 \%$ at $\sim 30 \mathrm{sccm}$ (Figures $4 \mathrm{~b}$ and S29). Lower flow rates reduced the selectivity, although ethylene production continued with an FE of $\sim 28 \%$, for the lowest $\mathrm{CO}_{2}$ flow rate of $3 \mathrm{sccm}$. At this low $\mathrm{CO}_{2}$ flow rate, the $3 \mathrm{D}$ CTPI produced an outlet gas stream with $37 \%$ ethylene (molar ratio) (Figure $4 \mathrm{~b}$ ). The comparative value at $80 \mathrm{sccm}$ is $1 \%$. The production of concentrated $\mathrm{CO}_{2} \mathrm{RR}$ products reduces downstream product separation/purification costs. ${ }^{6,19}$

The 3D CTPI catalyst was stable-presenting an average ethylene $\mathrm{FE}$ of $63 \%$ at a constant current density of $220 \mathrm{~mA}$ $\mathrm{cm}^{-2}$ for over $100 \mathrm{~h}$ of continuous operation (Figure $4 \mathrm{c}$ ). We found that the catalyst maintained its morphology and microstructure following the extended electrosynthesis (Figure S30).

By comparing the performance metrics presented herein with literature benchmarks (Figure 4d), we conclude that the 3D CTPI catalyst offers a means to achieve efficient, high-rate $\mathrm{CO}_{2}$-to-ethylene conversion in MEA electrolyzers.

In summary, this work devises a hierarchical adlayer structure that enables stable, selective $\mathrm{CO}_{2}$-to-ethylene conversion at high productivity and EE. Benefiting from the catalyst/tetrahydro-phenanthrolinium/ionomer augmentation, the structure offers improved $\mathrm{CO}_{2}$ availability and optimized adsorption of a key intermediate, CO. In an MEA electrolyzer this strategy achieved an ethylene $\mathrm{FE}$ of $66 \%$ at partial current densities $>200 \mathrm{~mA} \mathrm{~cm}{ }^{-2}$ and full-cell EE of $21 \%$. The tetrahydro-phenanthrolinium-augmentation approach extends the boundaries of what can be achieved in today's $\mathrm{CO}_{2} \mathrm{RR}$ MEA electrolyzers and sets out a path for future development.

\section{ASSOCIATED CONTENT}

\section{SI Supporting Information}

The Supporting Information is available free of charge at https://pubs.acs.org/doi/10.1021/acsenergylett.0c01266.

Experimental details and additional data (PDF)

\section{AUTHOR INFORMATION}

\section{Corresponding Authors}

Theodor Agapie - Joint Center for Artificial Photosynthesis and Division of Chemistry and Chemical Engineering, California Institute of Technology, Pasadena, California 91125, United States; ○orcid.org/0000-0002-9692-7614; Email: agapie@ caltech.edu

Jonas C. Peters - Joint Center for Artificial Photosynthesis and Division of Chemistry and Chemical Engineering, California Institute of Technology, Pasadena, California 91125, United States; @ orcid.org/0000-0002-6610-4414; Email: jpeters@ caltech.edu

Edward H. Sargent - Department of Electrical and Computer Engineering, University of Toronto, Toronto, Ontario M5S 3G4, Canada; (1) orcid.org/0000-0003-0396-6495;

Email: ted.sargent@utoronto.ca 
David Sinton - Department of Mechanical and Industrial Engineering, University of Toronto, Toronto, Ontario M5S 3G8, Canada; (1) orcid.org/0000-0003-2714-6408;

Email: sinton@mie.utoronto.ca

\section{Authors}

Adnan Ozden - Department of Mechanical and Industrial Engineering, University of Toronto, Toronto, Ontario M5S 3G8, Canada

Fengwang Li - Department of Electrical and Computer Engineering, University of Toronto, Toronto, Ontario M5S 3G4, Canada; orcid.org/0000-0003-1531-2966

F. Pelayo García de Arquer - Department of Electrical and Computer Engineering, University of Toronto, Toronto, Ontario M5S 3G4, Canada; 이이.org/0000-0003-2422-6234

Alonso Rosas-Hernández - Joint Center for Artificial Photosynthesis and Division of Chemistry and Chemical Engineering, California Institute of Technology, Pasadena, California 91125, United States

Arnaud Thevenon - Joint Center for Artificial Photosynthesis and Division of Chemistry and Chemical Engineering, California Institute of Technology, Pasadena, California 91125, United States

Yuhang Wang - Department of Electrical and Computer Engineering, University of Toronto, Toronto, Ontario M5S 3G4,

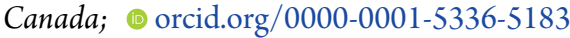

Sung-Fu Hung - Department of Electrical and Computer Engineering, University of Toronto, Toronto, Ontario M5S 3G4, Canada

Xue Wang - Department of Electrical and Computer Engineering, University of Toronto, Toronto, Ontario M5S 3G4, Canada

Bin Chen - Department of Electrical and Computer Engineering, University of Toronto, Toronto, Ontario M5S 3G4, Canada

Jun Li - Department of Mechanical and Industrial Engineering and Department of Electrical and Computer Engineering, University of Toronto, Toronto, Ontario M5S 3G8, Canada

Joshua Wicks - Department of Electrical and Computer Engineering, University of Toronto, Toronto, Ontario M5S 3G4, Canada

Mingchuan Luo - Department of Electrical and Computer Engineering, University of Toronto, Toronto, Ontario M5S 3G4, Canada

Ziyun Wang - Department of Electrical and Computer Engineering, University of Toronto, Toronto, Ontario M5S 3G4, Canada; O orcid.org/0000-0002-2817-8367

Complete contact information is available at: https://pubs.acs.org/10.1021/acsenergylett.0c01266

\section{Author Contributions}

${ }^{\perp}$ A.O. and F.L. contributed equally to this work. D.S. and E.H.S. supervised the project. A.O. conceived the idea and carried out the electrochemical experiments with advice from F.L.. A.T. and A.R.-H. synthesized and characterized the tetrahydro-phenanthrolinium. A.O. carried out Raman and EIS measurements. Y.W. and A.O. carried out SEM imaging. F.L. and S.F.H. designed the XAS measurements. S.-F.H. performed the XAS measurements. X.W. performed the NMR analysis and provided help in EIS measurements. B.C. and Y.W. performed the TEM analysis. J.W. performed XPS measurements. M.L., J.L., and Z.W. provided help in electrochemical experiments. A.O. and F.L. wrote the manuscript. F.P.G.A. provided help in manuscript writing. All authors discussed the results and assisted during manuscript preparation.

\section{Notes}

The authors declare no competing financial interest.

\section{ACKNOWLEDGMENTS}

This work was financially supported by the Ontario Research Fund: Research Excellence Program, the Natural Sciences and Engineering Research Council (NSERC) of Canada, the CIFAR Bio-Inspired Solar Energy program and the Joint Centre of Artificial Synthesis, a DOE Energy Innovation Hub, supported through the Office of Science of the US Department of Energy under award no. DE-SC0004993. X-ray absorption spectra were performed on SXRMB beamlines at the Canadian Light Source (CLS), which is supported by the Canada Foundation for Innovation, Natural Sciences and Engineering Research Council of Canada, the University of Saskatchewan, the Government of Saskatchewan, Western Economic Diversification Canada, the National Research Council Canada, and the Canadian Institutes of Health Research. The authors acknowledge Ontario Centre for the Characterization of Advanced Materials (OCCAM) for sample preparation and characterization facilities and thank Dr. Alexander H. Ip, Dr. Christine Gabardo and Mr. Colin P. O’Brien for useful discussions. A.T. acknowledges Marie Skłodowska-Curie Fellowship H2020-MSCA-IF-2017 (793471). J.L. acknowledges the Banting postdoctoral fellowship. D.S. acknowledges the NSERC E.W.R. Steacie Memorial Fellowship.

\section{REFERENCES}

(1) Hepburn, C.; et al. The technological and economic prospects for $\mathrm{CO}_{2}$ utilization and removal. Nature 2019, 575, 87-97.

(2) Birdja, Y. Y.; et al. Advances and challenges in understanding the electrocatalytic conversion of carbon dioxide to fuels. Nat. Energy 2019, 4, 732-745.

(3) Ren, S.; et al. Molecular electrocatalysts can mediate fast, selective $\mathrm{CO}_{2}$ reduction in a flow cell. Science 2019, 365, 367-369.

(4) De Luna, P.; et al. What would it take for renewably powered electrosynthesis to displace petrochemical processes? Science 2019, 364, eaav3506.

(5) Wang, Y.; et al. Catalyst synthesis under $\mathrm{CO}_{2}$ electroreduction favours faceting and promotes renewable fuels electrosynthesis. Nat. Catal. 2020, 3, 98-106.

(6) Xia, C.; et al. Continuous production of pure liquid fuel solutions via electrocatalytic $\mathrm{CO}_{2}$ reduction using solid-electrolyte devices. Nat. Energy 2019, 4, 776-785.

(7) Kauffman, D. R.; Alfonso, D. Directing $\mathrm{CO}_{2}$ conversion with copper nanoneedles. Nat. Catal. 2018, 1, 99-100.

(8) Jouny, M.; Hutchings, G. S.; Jiao, F. Carbon monoxide electroreduction as an emerging platform for carbon utilization. Nat. Catal. 2019, 2, 1062-1070.

(9) Verma, S.; Kim, B.; Jhong, H.; Ma, S.; Kenis, P. J. A. A Grossmargin model for defining technoeconomic benchmarks in the electroreduction of $\mathrm{CO}_{2}$. ChemSusChem 2016, 9, 1972-1979.

(10) Jouny, M.; Luc, W.; Jiao, F. General techno-economic analysis of $\mathrm{CO}_{2}$ electrolysis systems. Ind. Eng. Chem. Res. 2018, 57, 21652177.

(11) Hori, Y. In Modern Aspects of Electrochemistry; Vayenas, C. G. et al., Eds.; Springer, 2008; Vol. 42, pp 89-189.

(12) Gao, D.; Arán-Ais, R. M.; Jeon, H. S.; Cuenya, B. R. Rational catalyst and electrolyte design for $\mathrm{CO}_{2}$ electroreduction towards multicarbon products. Nat. Catal. 2019, 2, 198-210. 
(13) Dinh, C.; et al. $\mathrm{CO}_{2}$ electroreduction to ethylene via hydroxidemediated copper catalysis at an abrupt interface. Science 2018, 360, $783-787$.

(14) Hoang, T. T. H.; et al. Nanoporous copper-silver alloys by additive-controlled electrodeposition for the selective electroreduction of $\mathrm{CO}_{2}$ to ethylene and ethanol. J. Am. Chem. Soc. 2018, 140, 57915797.

(15) Li, F.; et al. Cooperative $\mathrm{CO}_{2}$-to-ethanol conversion via enriched intermediates at molecule-metal catalyst interfaces. Nat. Catal. 2020, 3, 75-82.

(16) Weekes, D. M.; Salvatore, D. A.; Reyes, A.; Huang, A.; Berlinguette, C. P. Electrolytic $\mathrm{CO}_{2}$ reduction in a flow cell. Acc. Chem. Res. 2018, 51, 910-918.

(17) Higgins, D.; Hahn, C.; Xiang, C.; Jaramillo, T. F.; Weber, A. Z. Gas-diffusion electrodes for carbon dioxide reduction: a new paradigm. ACS Energy Lett. 2019, 4, 317-324.

(18) Gabardo, C. M.; et al. Continuous carbon dioxide electroreduction to concentrated multi-carbon products using a membrane electrode assembly. Joule 2019, 3, 2777-2791.

(19) Ripatti, D. S.; Veltman, T. R.; Kanan, M. W. Carbon monoxide gas diffusion electrolysis that produces concentrated $\mathrm{C}_{2}$ products with high single-pass conversion. Joule 2019, 3, 240-256.

(20) Weng, L.; Bell, A. T.; Weber, A. Z. Towards membraneelectrode assembly systems for $\mathrm{CO}_{2}$ reduction: a modeling study. Energy Environ. Sci. 2019, 12, 1950-1968.

(21) Carmo, M.; Fritz, D. L.; Mergel, J.; Stolten, D. A comprehensive review on PEM water electrolysis. Int. J. Hydrogen Energy 2013, 38, 4901-4934.

(22) Debe, M. K. Electrocatalyst approaches and challenges for automotive fuel cells. Nature 2012, 486, 43-51.

(23) Ozden, A.; Shahgaldi, S.; Li, X.; Hamdullahpur, F. A review of gas diffusion layers for proton exchange membrane fuel cells-With a focus on characteristics, characterization techniques, materials and designs. Prog. Energy Combust. Sci. 2019, 74, 50-102.

(24) Li, F.; et al. Molecular tuning of $\mathrm{CO}_{2}$-to-ethylene conversion. Nature 2020, 577, 509-513.

(25) Merino-garcia, I.; Albo, J.; Solla-Gullón, J.; Montiel, V.; Irabien, A. $\mathrm{Cu}$ oxide/ZnO-based surfaces for a selective ethylene production from gas-phase $\mathrm{CO}_{2}$ electroconversion. J. CO2 Util. 2019, 31, 135142.

(26) Montoya, J. H.; Shi, C.; Chan, K.; Norskov, J. K. Theoretical insights into a $\mathrm{CO}$ dimerization mechanism in $\mathrm{CO}_{2}$ electroreduction. J. Phys. Chem. Lett. 2015, 6, 2032-2037.

(27) Calle-vallejo, F.; Koper, M. T. M. Theoretical considerations on the electroreduction of $\mathrm{CO}$ to $\mathrm{C}_{2}$ species on $\mathrm{Cu}(100)$ electrodes. Angew. Chem., Int. Ed. 2013, 52, 7282-7285.

(28) Gu, J.; Hu, X. Homogeneous reactions limit the efficiency of gold electrodes in $\mathrm{CO}_{2}$ electroreduction. ACS Cent. Sci. 2019, 5, 933935.

(29) Burdyny, T.; Smith, A. W. $\mathrm{CO}_{2}$ reduction on gas-diffusion electrodes and why catalytic performance must be assessed at commercially-relevant conditions. Energy Environ. Sci. 2019, 12, $1442-1453$

(30) Huang, J.; Li, Z.; Zhang, J. Review of characterization and modeling of polymer electrolyte fuel cell catalyst layer: the blessing and curse of ionomer. Front. Energy. 2017, 11, 334-364.

(31) Ott, S.; et al. Ionomer distribution in porous carbon-supported catalyst layers for high-power and low Pt-loaded proton exchange membrane fuel cells. Nat. Mater. 2020, 19, 77-85.

(32) Kusoglu, A.; Weber, A. Z. New insights into perfluorinated sulfonic-acid ionomers. Chem. Rev. 2017, 117, 987-1104.

(33) Siracusano, S.; et al. Performance analysis of short-side-chain Aquivion ${ }^{\circledR}$ perfluorosulfonic acid polymer for proton exchange membrane water electrolysis. J. Membr. Sci. 2014, 466, 1-7.

(34) García de Arquer, F. P.; et al. $\mathrm{CO}_{2}$ electrolysis to multicarbon products at activities greater than $1 \mathrm{~A} \mathrm{~cm}^{-2}$. Science 2020, 367, 661667.

(35) Thevenon, A.; Rosas-Hernández, A.; Peters, J. C.; Agapie, T. In-situ nanostructuring and stabilization of polycrystalline copper by an organic salt additive promotes electrocatalytic $\mathrm{CO}_{2}$ reduction to ethylene. Angew. Chem., Int. Ed. 2019, 58, 16952-16958.

(36) Li, J.; et al. Constraining CO coverage on copper promotes high-efficiency ethylene electroproduction. Nat. Catal. 2019, 2, $1124-1131$

(37) Jouny, M.; Luc, W.; Jiao, F. High-rate electroreduction of carbon monoxide to multi-carbon products. Nat. Catal. 2018, 1, 748755.

(38) Xiao, H.; Cheng, T.; Goddard, W. A. Atomistic mechanisms underlying selectivities in $\mathrm{C}_{1}$ and $\mathrm{C}_{2}$ products from electrochemical reduction of $\mathrm{CO}$ on $\mathrm{Cu}(111)$. J. Am. Chem. Soc. 2017, 139, 130-136.

(39) Wang, X.; et al. Mechanistic reaction pathways of enhanced ethylene yields during electroreduction of $\mathrm{CO}_{2}-\mathrm{CO}$ co-feeds on $\mathrm{Cu}$ and Cu-tandem electrocatalysts. Nat. Nanotechnol. 2019, 14, 10631070.

(40) Xu, Y.; et al. Oxygen-tolerant electroproduction of $\mathrm{C}_{2}$ products from simulated flue-gas. Energy Environ. Sci. 2020, 13, 554-561.

(41) $\mathrm{Lu}, \mathrm{X}$.; et al. A bio-inspired $\mathrm{O}_{2}$-tolerant catalytic $\mathrm{CO}_{2}$ reduction electrode. Sci. Bull. 2019, 64, 1890-1895.

(42) Luc, W.; et al. $\mathrm{SO}_{2}$-induced selectivity change in $\mathrm{CO}_{2}$ electroreduction. J. Am. Chem. Soc. 2019, 141, 9902-9909. 